NASA Technical Memorandum 86455

Nighttime Observations of Thunderstorm Electrical Activity

From a High Altitude Airplane

M. Brook, C. Rhodes, O. H. Vaughan, Jr., R. E. Orville, and B. Vonnegut 
NASA Technical Memorandum 86455

\section{Nighttime Observations of Thunderstorm Electrical Activity From a High Altitude Airplane}

M. Brook and C. Rhodes

Geophysical Research Center

New Mexico Institute of Mining and Technology

Socorro, New Mexico

O. H. Vaughan, Jr.

George C. Marshall Space Flight Center

Marshall Space Flight Center, Alabama

R. E. Orville and B. Vonnegut

State University of New York at Albany

Albany, New York

\section{N/Sก}

National Aeronautics

and Space Administration

Scientific and Technical

Information Branch

1984 


\section{ACKNOWLEDGMENTS}

We thank J. C. Dodge of NASA Headquarters who supported our efforts and arranged for the use of the U-2 aircraft. We are grateful for the cooperation and help from NASA Ames Research Center personnel, J. Arvesen and J. Cherbonneaux. Pilots were I. B. Webster, who flew over the Arkansas storm; J. A. Barnes, who flew over the Georgia storm; and $R$. Erickson. We recognize the contribution of the ground crew of the NASA U-2 airplane who, through their skill and long hours of hard work, maintained the instrumentation in good operating condition. We are indebted to David Rust and his associates at the National Severe Storms Laboratory in Norman, Oklahoma, for their cooperation and helpful forecasts and to Lance Bosart of SUNYA for his interpretation of the synoptic situations producing the storms. We thank Joe Alloway of New Mexico Tech for having constructed the photocell and slow antenna instrumentation for the aircraft, and Ruth A. Duggan for help with the data analysis. We appreciate the continuing support of the National Aeronautics and Space Administration (Contracts NAS8-32893, NAS8-33380, and NAS8-33817), the Office of Naval Research (Contracts N00014-80-C-0312 and N00014-84-K-0069), the National Science Foundation (Grants ATM7921080, ATM8026533, and ATM8117665), and the U. S. Air Force (Air Force Cambridge Research Laboratories, Contract F19628-78C-0007), which made this work possible. 


\section{TABLE OF CONTENTS}

Page

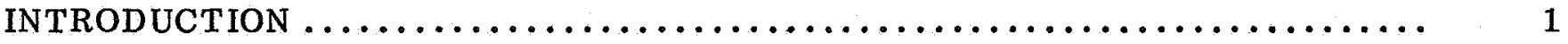

INSTRUMENTATION $\ldots \ldots \ldots \ldots \ldots \ldots \ldots \ldots \ldots \ldots \ldots \ldots \ldots \ldots \ldots \ldots \ldots \ldots \ldots \ldots \ldots \ldots . . \ldots$

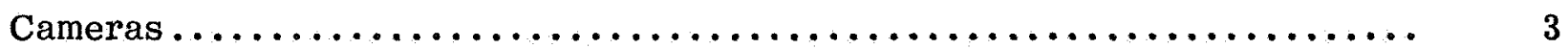

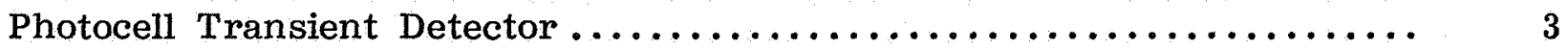

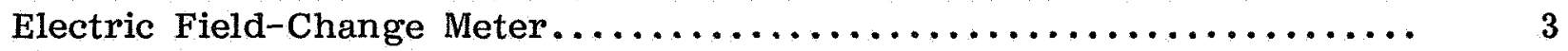

Linear Diode Array Spectrometer ....................... 4

OBSERVATIONS $\ldots \ldots \ldots \ldots \ldots \ldots \ldots \ldots \ldots \ldots \ldots \ldots \ldots \ldots \ldots \ldots \ldots \ldots \ldots \ldots \ldots \ldots \ldots \ldots \ldots$

The Arkansas Storm $\ldots \ldots \ldots \ldots \ldots \ldots \ldots \ldots \ldots \ldots \ldots \ldots \ldots \ldots \ldots \ldots \ldots \ldots$

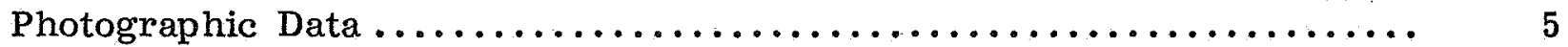

Optical and Electric Field-Change Data..................... 5

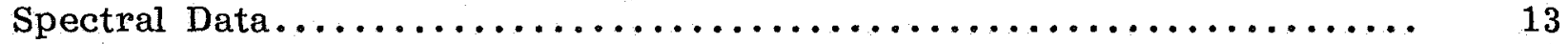

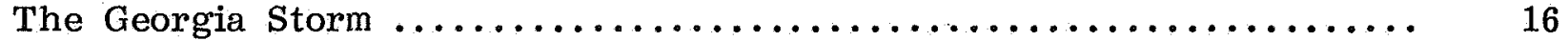

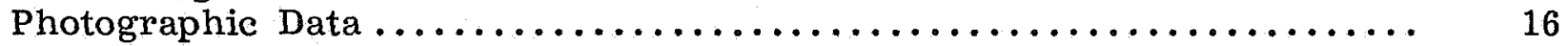

Optical and Electric Field-Change Data..................... 16

Spectral Data..................................... 22

DISCUSSION AND CONCLUSIONS $\ldots \ldots \ldots \ldots \ldots \ldots \ldots \ldots \ldots \ldots \ldots \ldots \ldots \ldots \ldots \ldots . \ldots \ldots$

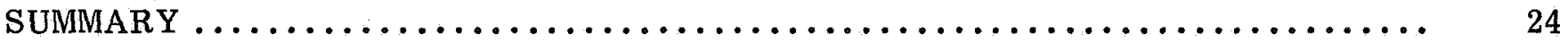

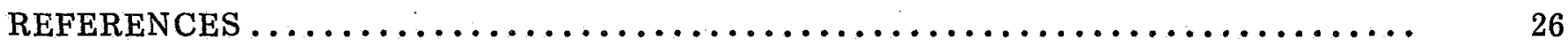




\section{LIST OF ILLUSTRATIONS}

Figure

Title

Page

1. Convective cloud turret of Arkansas Storm (approximately $15 \mathrm{~km}$ msl altitude) illuminated by lightning within the cloud ...........

2. Lightning channel in clear air bridging crease in cauliflower turret .........................................

3. Lightning channels apparently terminating in clear air ......... 8

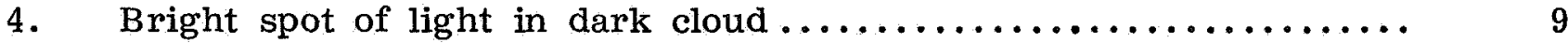

5. Optical sensor and electric field-change data from a flash to ground near Little Rock, Arkansas ......................

6. Optical and E field-change signal from an intracloud lightning flash recorded by a U-2 aircraft flying at an elevation of $20 \mathrm{~km}$ above a storm near Little Rock, Arkansas..............

7. Flash occurring while film was moving so that five strokes in one channel and four strokes in a second channel of the flash are resolved......................................

8. Original slitless spectrum negative is shown on a video densitometer.....................................

9. Convective cloud turret of Georgia storm (approximately $11 \mathrm{~km}$ msl altitude) illuminated by lightning in the cloud ............

10. Lightning channels visible in creases of cloud $\ldots \ldots \ldots \ldots \ldots \ldots \ldots$

11. Rather faint lightning channels apparently terminating in clear air

12. Optical, electric field, and spectral data from a flash to ground

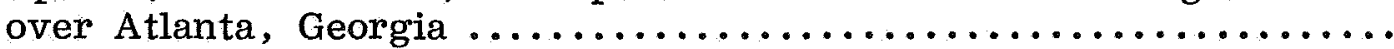

13. Photograph of cloud illuminated by two discharges, one which produced the data shown in Figure $12 \ldots \ldots \ldots \ldots \ldots \ldots \ldots \ldots \ldots$ 
TECHNICAL MEMORANDUM

\section{NIGHTTIME OBSERVATIONS OF THUNDERSTORM ELECTRICAL ACTIVITY FROM A HIGH ALTITUDE AIRPLANE}

\section{INTRODUCTION}

Airplane and balloon observations have confirmed C. T. R. Wilson's prediction that strong electric fields exist over the tops of thunderstorms [2]. Photographs from airplanes made in the daytime in conjunction with electric field measurements show that the most intense electrical stresses are associated with the penetrative convective cells that rise above the cirriform anvil $[3,4]$.

At the tops of thunderstorms there is undoubtedly strong electrical activity, but there are only a few observations concerning lightning or other kinds of dielectric breakdown that may be taking place. Descriptions of discharges in the clear air above the clouds are to be found in texts on atmospheric electricity. Schonland [5] tells of a brilliant ball of light observed at the top of a bank of clouds which pulsated in size and intensity for over $15 \mathrm{~min}$. He also described what appears to be a form of glow discharge which extended from the top of a cloud to the upper air and was seen to occur regularly at the same time as flashes to ground.

Chalmers [6] cites visual evidence of possible discharges toward the electrosphere reported by Boys, Malan, Wood, Reynolds, and Hoffman, as well as observations of radar reflections by Rumi and Atlas, which may have originated from such discharges. Uman [7] cites three additional observations of discharges that extended upward from the tops of thunderclouds.

In private communications we have learned of similar independent observations of glow-like discharges above severe storms from C. B. Moore of New Mexico Tech and from Floyd Montgomery, formerly an observer for the U.S. Weather Bureau. Recently, Ronald Williams [8] has described a lightning-like discharge from the top of a cloud into the stratosphere which he saw at night while flying a U-2 airplane at approximately $20 \mathrm{~km}$ altitude. Similar observations from airplanes by Roberts [9] and Gales [10] have been published.

Possibly related to such observations is a phenomenon sometimes observed in which the clear atmosphere above a vigorous storm can be seen to give off a flickering light. This may possibly be light from the lightning discharges that is being scattered by aerosol particles in the stratosphere. Alternatively, it is conceivable that such light may originate as the result of glow-like electrical discharges in the rarified upper atmosphere. That such discharges could exist in the clear air above a thundercloud seems plausible, for the largest and most electrically active thunderclouds are known to rise to altitudes in excess of $20 \mathrm{~km}$, where the atmospheric pressure and hence the dielectric breakdown strength is less than $1 / 10$ th that at sea level. Furthermore, as C. T. R. Wilson [11] has pointed out, the dielectric strength of the air will decrease more rapidly with altitude than will the electric field perturbations that result from lightning. It therefore appears conceivable that discharges might take place in the stratosphere some distance above the cloud. 
Although the number of observations of discharges in the clear air above the cloud is small, they probably occur more often than might at first be supposed, for observers rarely have a clear view of a thunderstorm cloud top. Schonland [5] may be correct in his suggestion that though this type of air discharge is rarely reported, it may not be uncommon.

Photographs of the lightning associated with the upper part of a thundercloud would be of help in understanding this phenomenon, but they are rare. For example, no such picture of lightning is to be found in Salanave's beautiful new atlas of lightning photographs [12]. The dearth of such pictures is not surprising. The upper parts of large storms are usually shielded from the view of ground observers by low-level clouds or by widespreading anvils. From aircraft, photography looking down at cloud tops is usually not feasible, for the most intense electrical storms attain heights well above the ceilings of all but a few specialized high-altitude airplanes. Even when the top of the cloud is in clear view, either from the ground or from an airplane, photographing lightning during the day poses problems, for the lightning channel is hardly visible when viewed against the sky or the bright background of a sunlit cloud.

There can be little question that a better knowledge of the electrical activity in the upper part of the cloud and its relationship to the convective structure of the storm is important to an understanding of thunderstorms. These discharges may not only be important in the electrical budget of the cloud, but may also play a significant role in introducing oxides of nitrogen and other chemical compounds directly into the stratosphere.

Astronauts in the past have described spectacular lightning occurring in the tops of thunderstorms [13]. These observations show that an orbiting spacecraft is a valuable platform from which to observe the electrical activity in clouds. To provide more detailed data from such observations, we have made arrangements to have astronauts on space shuttle flights take pictures of thunderstorms and lightning with a motion picture camera and to utilize a photocell optical system to secure information on the frequency and character of lightning discharges [14,15]. More recently, the possibility of making meaningful lightning measurements from a geosynchronous satellite has been discussed [16].

In order to provide background data and ground truth information that would be helpful in the interpretation of satellite data and in the design of new satellite instrumentation, we have made several flights over active thunderstorm cells with a NASA U-2 airplane instrumented for electrical and optical observations. The results of the first of these flights, which was made over a thunderstorm in New Mexico during the day, have been reported [17].

This report describes two subsequent sets of observations that were made looking down at night from the U-2 airplane, which was flying at an altitude of about $20 \mathrm{~km}$ and a true air speed of $200 \mathrm{~m} \mathrm{sec}^{-1}$. The first of these on 17 May 1980 was made over a vigorous thunderstorm taking place $160 \mathrm{~km}$ northwest of Little Rock, Arkansas, and the second on 11 May 1981 over a thunderstorm near Atlanta, Georgia. 


\section{INSTRUMENTATION}

\section{Cameras}

Three Vinten cameras, normally employed for aerial photography of the ground from the U-2 aircraft, were used to photograph thunderstorms and lightning. Each of these, which looks directly down from the airplane, has an $\mathrm{f} / 2.8$ lens of $44.5 \mathrm{~mm}$ focal length and uses $70 \mathrm{~mm}$ film, giving a format of $56 \times 57 \mathrm{~mm}$. When the airplane is at its operating altitude of $20 \mathrm{~km}$, the ground coverage is about $26 \times 26 \mathrm{~km}$. For clouds at intermediate altitudes, such as are described in this report, the coverage is approxiamtely $10 \times 10 \mathrm{~km}$.

For photography of the Arkansas storm, all cameras were loaded with black and white film, the first with Plus-X Aerographic 2402 to bring out cloud details, the second with Infrared Aerographic 2424 to determine if this film offered any particular advantages for cloud photography at night, and the third with Panatomic-X Aerial 3400 film to give the maximum resolution of the lightning discharge. This camera was also equipped with a 300 lines $/ \mathrm{mm}$ diffraction grating placed over the lens to provide slitless spectra when lightning channels were visible in the field of view.

For the daytime photography of thunderstorms, the cameras were operated in their normal mode, exposing snapshots in unison, and advancing the film between exposures. For night photography of thunderstorms and lightning the shutters were removed. In the flight over the Arkansas storm, the cameras were actuated by the pilot, a procedure which proved satisfactory for lightning photography.

The photographic procedures were modified slightly for the flight over the second storm made near Atlanta, Georgia. An intervalometer was used to expose each frame for $11 \mathrm{sec}$. In one of the cameras, Eastman SO 397 color film was used instead of high-speed black and white film to facilitate the interpretation of spectra produced by the diffraction gratings, which, on this flight, were placed over the lenses of the color camera and of the infrared camera.

\section{Photocell Transient Detector}

A silicon solar cell looking downward through a glass window was used to provide electrical signals for recording the details of the optical transients produced by lightning. A red to near infrared optical filter (Baird Atomic D-645) having 85 percent of maximum transmission at $\lambda=656 \mathrm{~nm}$ was placed in front of the photocell. An absolute calibration of the filter plus photocell unit gave a sensitivity of $0.31 \mathrm{~A} / \mathrm{W}$ into a $5 \mathrm{ohm}$ load. This equipment is identical to that which was used in daylight observations of lightning from a U-2 [17]. High gain and low gain channels were used to record the large dynamic range of the signals.

\section{Electric Field-Change Meter}

Because measurements of the electric field changes are valuable in the diagnosis of the various processes taking place in the lightning flash, an electric field-change meter was also installed behind the down-facing window of the U-2 aircraft. The meter consisted of a flat-plate sensor of area $300 \mathrm{~cm}^{2}$ connected to a charge amplifier 
with a 3 sec time constant. Three output channels set to different gains were used to cover the dynamic range of the E-field signals. The rise-time of the meter from 10 to 90 percent amplitude was less than 100 nanosec.

\section{Linear Diode Array Spectrometer}

In order to supplement the spectroscopic data being recorded on film, a linescan camera employing a 300 lines $/ \mathrm{mm}$ grating and a 1728 linear diode array was installed in the lower bulkhead. This equipment (Fairchild Line-Scan Camera Model CCD 1300) generated spectral data as a video signal that was recorded along with the photocell and the E-field data on a Bell and Howell $\mathrm{M}-14 \mathrm{E}$ tape recorder. Data were taken at a tape speed of 30 ips. The slow tape speed compromised the bandwidth available with the wideband II electronics, but was used in order to achieve longer total recording time.

The optical and the E-field data recorded at 30 ips do not exhibit the lightning fine-structure present, for example, in the E-field data of Guo and Krider [18] who, using ground based equipment, studied the relationship of the light emitted to the accompanying electric field signatures of return-strokes. In general, it was found that the rise time of the optical signals was slow, much slower than the measured 10 to 90 percent value of $1.6 \mu \mathrm{sec}$ of the optical sensor, and comparable with the rise times associated with the return strokes as given in Reference 18 . There are several reasons for the apparent dilation of the optical signals when measured with a sensor looking down at the thundercloud: the leader and the return-stroke channels are usually not seen directly, but, as they extend their length, multiple scattering coupled with the large dimension of the cloud and the finite velocity of light results in a lengthening of the light emitting channel and in multipaths that contribute to a "stretched signal." Thus, lightning optical studies that use a horizontal slit to view a small portion of the luminous channel, such as discussed in Beasely, et al. [19] probably measure the true optical risetime in that portion of the channel. The wide angle optical detector (120 deg) used on the U-2 viewing primarily scattered light emerging from the cloud top was probably more of a determining factor in the measured slow rise times than was the reduced recording speed. On the other hand, since one major objective of this study was simply to resolve leaders from return-strokes, the 30 ips tape speed was more than adequate for the purpose. The lack of greater detail in the E-field signal is due in part to the necessity for smoothing the data to reduce the large amount of spurious noise picked up by the meter from various sources in the U-2 aircraft bay.

\section{OBSERVATIONS}

\section{The Arkansas Storm}

At 0000 GMT 17 May 1980 (about $3 \mathrm{hr}$ prior to flight time), the surface weather map featured a $1006 \mathrm{mb}$ low centered in south central Kansas. A trailing cold front extended southeastward across extreme eastern Oklahoma and then southward into Texas. A warm front extended eastward from the low across southern Missouri. The flight target area of the U-2 aircraft was in the apex of the warm section of the storm. Farther south an intense mesoscale convective complex was located along the southern Louisiana coast and was responsible for 4 to $8 \mathrm{~cm}$ rains in the last $6 \mathrm{hr}$ at several locations. 
Surface winds in the target area were southeasterly between 2 to $4 \mathrm{~m} \mathrm{~s}^{-1}$ at $0000 \mathrm{GMT}$. Surface dewpoints were near $20^{\circ} \mathrm{C}$ with air temperatures around $25^{\circ} \mathrm{C}$. A local moisture maximum was observed at $850 \mathrm{mb}$ at Little Rock (72340) with a mixing ratio of $12 \mathrm{~g} \mathrm{~kg}^{-1}$ and a southerly wind of $10 \mathrm{~m} \mathrm{~s}^{-1}$. In the upper troposphere a broad southwesterly flow was evident ahead of a vigorous trough located in western

Texas. $200 \mathrm{mb}$ winds were southwesterly at $45 \mathrm{~m} \mathrm{~s}^{-1}$ over the target area.

The Arkansas convection formed just ahead of the cold front and on the back edge of the intense convective complex to the southeast. The Showalter index at 0000 GMT 17 May 1982 was $0,-5$ and -5 at Longview, Texas (72247), Little Roek, Arkansas (72340), and Monett, Missouri (72349), respectively. The most unstable air was found over western Arkansas and southwestern Missouri where the low level moisture maximum was capped by dry air in the 700 to $500 \mathrm{mb}$ layer.

\section{Photographic Data}

On this flight, the camera was operated by the pilot. When he flew over the storm and if lightning was occurring, he would actuate the camera. Because the LED timer was not operative, the time of each exposure is not known, and correlations cannot be made between the photographs and the data taken with the other instruments.

When the lightning within the storm was sufficiently intense, the entire cloud surface in the field of view of the camera was illuminated and revealed the cauliflowerlike structure typical of a strongly convective turret. Figure 1 shows such a cloud. The distance scale given is only approximate, as it is calculated from the height of the cloud, which was estimated by the pilot to be at about $14 \mathrm{~km}$.

In most photographs, the lightning channels lie entirely beneath the visible cloud surface, and cannot be seen. In some photographs, perhaps 10 percent of the total, a portion of the sharp bright channel of an electric discharge is clearly visible. Figure 2 shows the most common situation in which a section of the channel can be seen coming out of one part of the cloud, crossing an open crease or valley in the cloud, and then re-entering the cloud on the opposite side. Two strokes in the same channel are visible because the discharges occurred while the film was being transported past the unshuttered lens. Occasionally, as is shown in Figure 3 , a lightning channel can be seen to terminate in the clear air. Figure 4 shows a bright spot, which is perhaps produced when the light escapes through a hole in the cloud.

\section{Optical and Electric Field-Change Data}

Figure 5(0) shows the optical and electric field signal for a lightning flash with 5 strokes to ground, which occurred on Day 138 at 02:25:22 in the morning. Because we have no ground-truth data, the identification of the flash as a flash to ground is an interpretation based on the similarity of these field changes to others recorded and verified at ground level. The E-field-change record shown in Figure 5(0) exhibits 5 downward-going abrupt deflections each indicative of a return-stroke equivalently lowering negative charge to Earth (or raising positive charge to the cloud). Each stroke is labeled in the order of occurrence, and is shown on an expanded time base in Figures $5(1)$ to $5(5)$. The abrupt E-field changes are each accompanied by an optical signal, which is also shown expanded in the figures. 


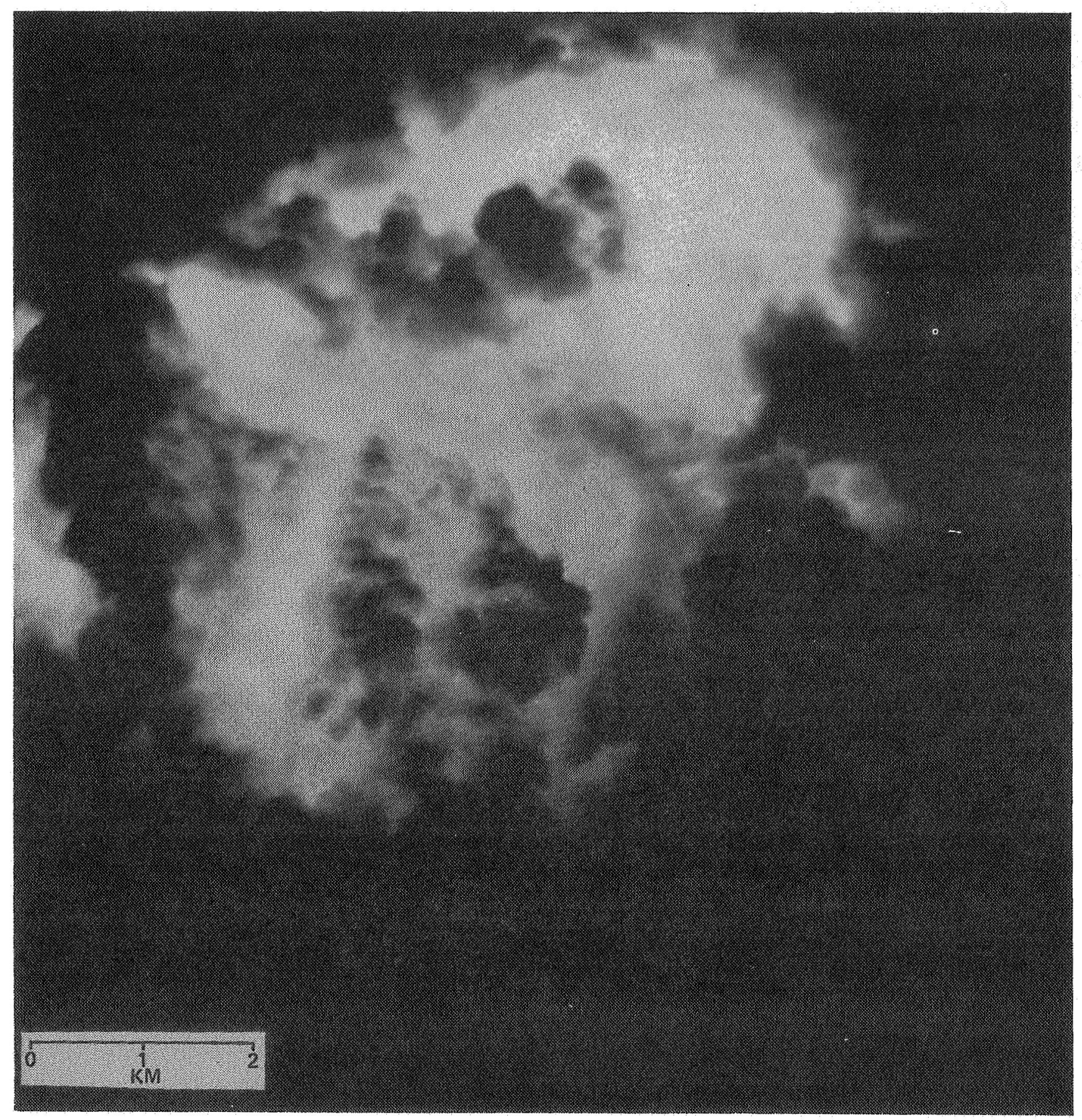

Figure 1. Convective cloud turret of Arkansas Storm (approximately $15 \mathrm{~km}$ msl altitude) illuminated by lightning within the cloud. 


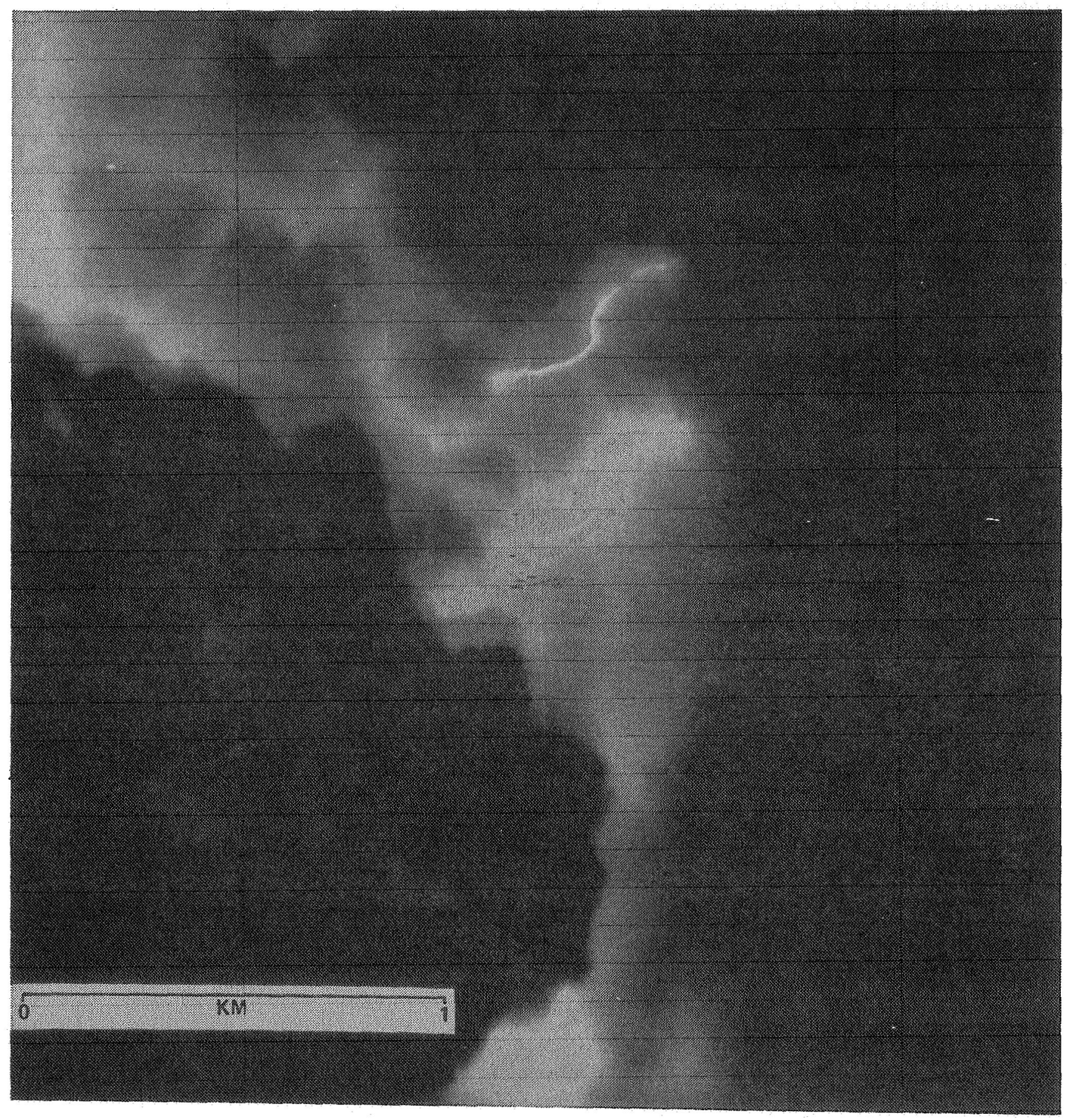

Figure 2. Lightning channel in clear air bridging crease in cauliflower turret. Double image is produced by two strokes in the same channel that took place during transport of film past the open shutter. 


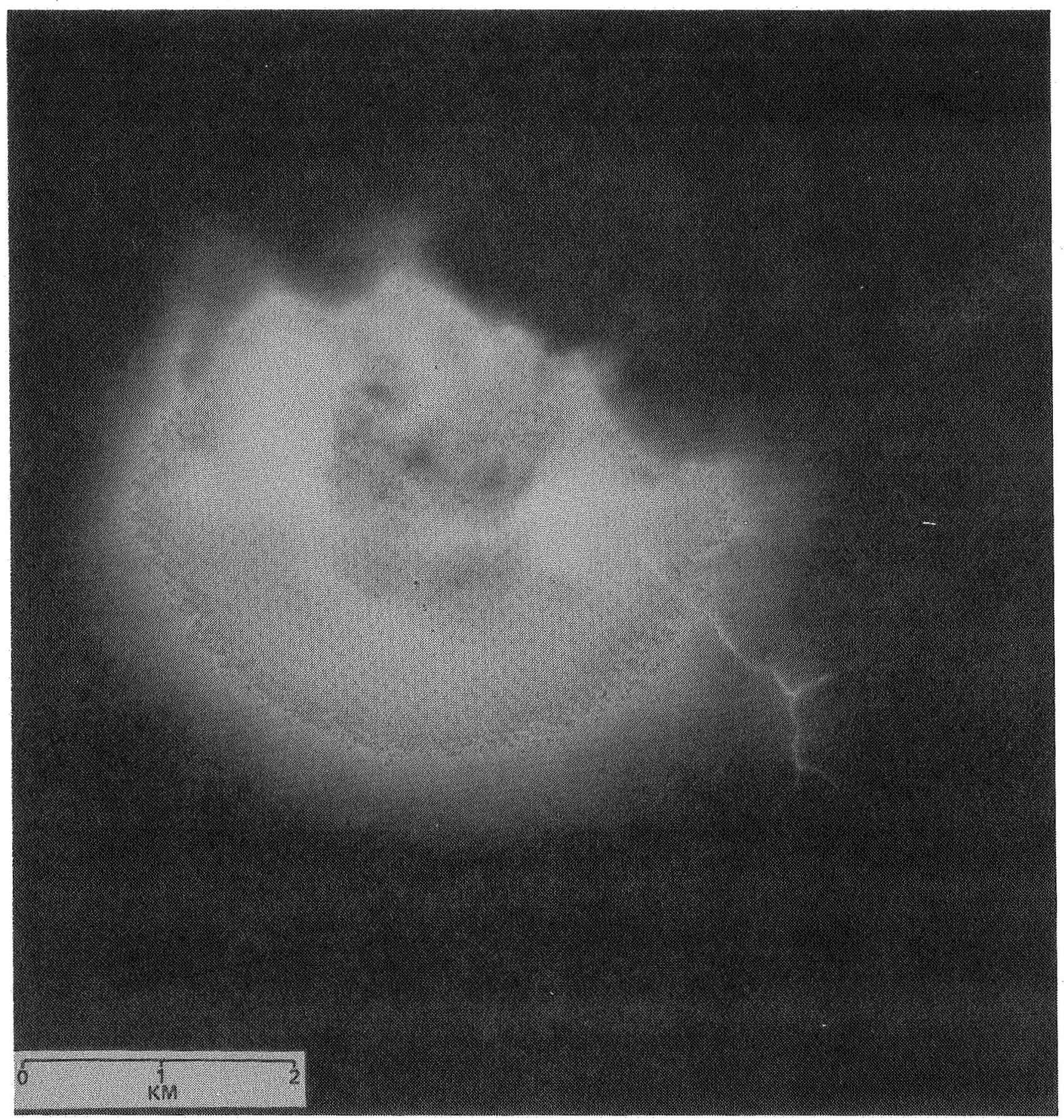

Figure 3. Lightning channels apparently terminating in clear air. 


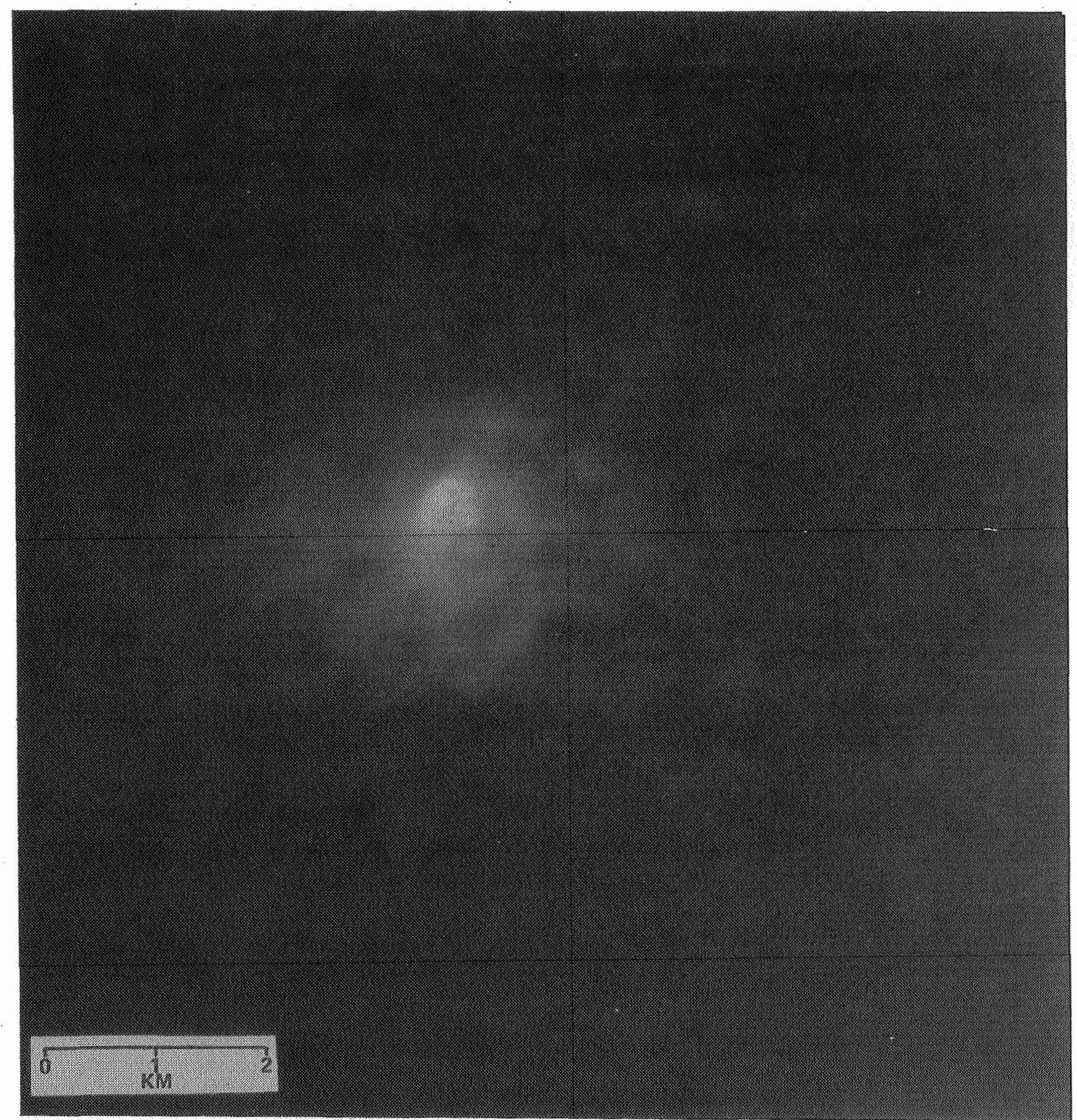

Figure 4. Bright spot of light in dark cloud. 

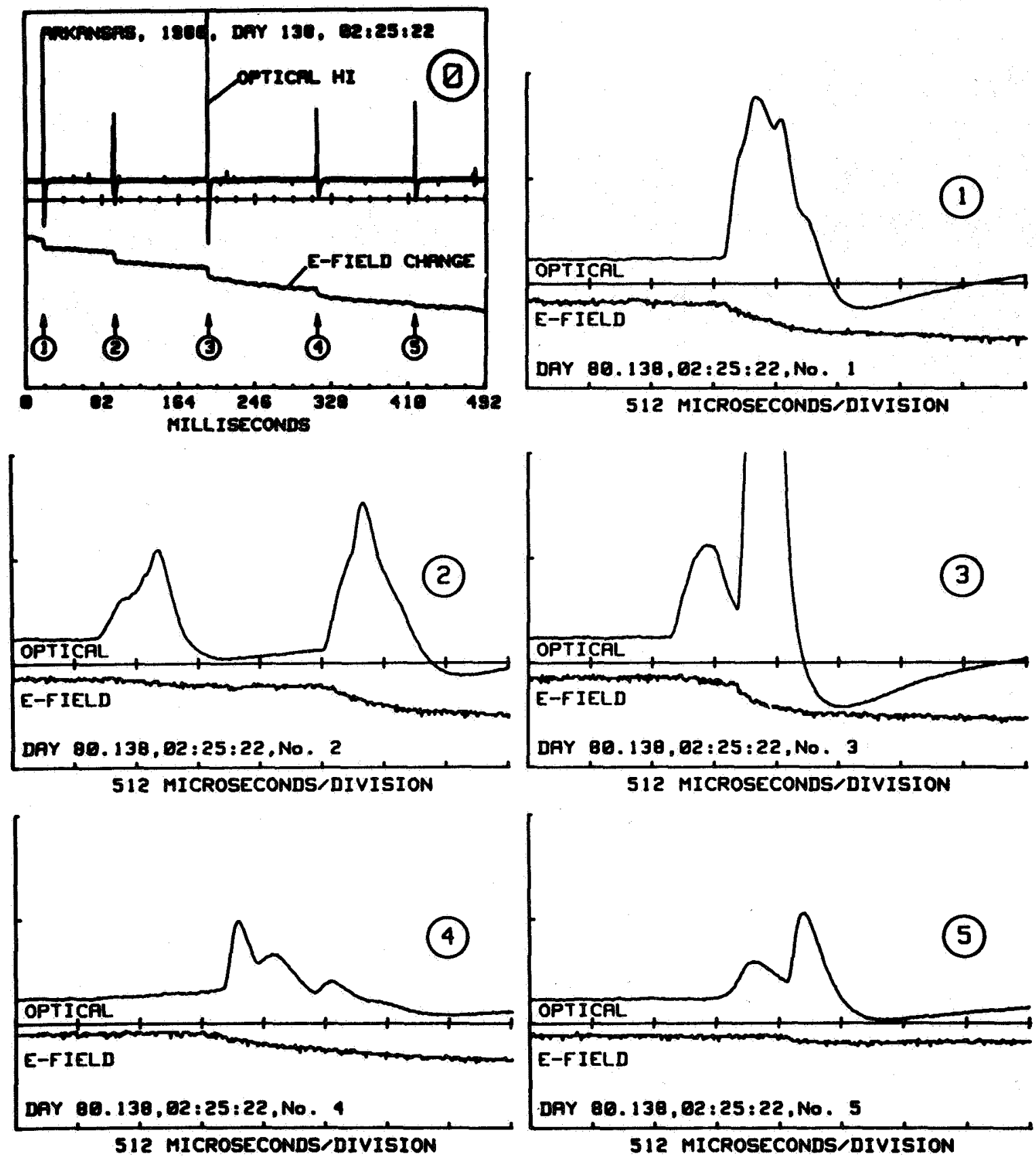

Figure 5. Optical sensor and electric field-change data from a flash to ground near Little Rock, Arkansas. The U-2 aircraft was flying at an elevation of $20 \mathrm{~km}$. Figure 5(0) shows the sensor data for the entire flash. Figure 5(1) through 5(5) are expanded views of the signals from the individual strokes. 
Focusing attention on the first stroke, in Figure $5(0)$, it is noted that the E-field signal shows a small downward-going trend for about $15 \mathrm{msec}$ prior to the return stroke. This deflection is probably associated with a stepped leader: not only does it appear before the first stroke of the flash, but its duration of $15 \mathrm{msec}$ is very much what is expected for stepped leaders. In the expanded time base of Figure 5(1), about $1.5 \mathrm{msec}$ of the leader field change is shown. About $600 \mu \mathrm{sec}$ of activity is discernible in the E-field record immediately prior to the stroke, and this appears primarily as a smooth downward trend without pulsative noise because, as explained earlier, the noise environment required that the E-field data be smoothed. The optical signal accompanying the stepped leader was apparently too weak to be recorded. The optical signal for the return-stroke portion is strong, and exhibits a complex structure for a duration somewhat less than $1 \mathrm{msec}$. This type of structure was attributed by Guo and Krider [18] to the occurrence of branches. From the above-cloud view, it is difficult to attribute, with certainty, the obviously multiple and superimposed signals to a specific source such as below-cloud branching in the return-stroke channel. As seen from above the cloud, below-cloud branching would be very strongly attenuated. In-cloud branching is perhaps a more likely source.

In Figure 5(2), the second return-stroke is preceded by a leader of about $1.6 \mathrm{msec}$ duration as seen in the E-field trend. The optical return-stroke signal is also preceded by a light pulse that occurs simultaneously with the E-field leader signal. The $1.7 \mathrm{msec}$ separation between the leader and return-stroke optical signals is somewhat long but still consistent with the well established dart-leader, returnstroke sequence. The dart leader optical signal peak and the following return to zero - all prior to the return-stroke - is interesting and will be discussed presently.

The third stroke, Figure 5(3), is an excellent example of the dart-leader, return-stroke sequence in both the optical and E-field signals. The large optical return-stroke signal is seen to go off-scale. In this sequence, the dart leader peak occurred about $500 \mu \mathrm{sec}$ prior to the return-stroke peak.

The fourth stroke exhibits a complex optical return-stroke signal preceded by a discernible luminosity. There seems to be no accompanying E-field deflection prior to the return-stroke; the long time interval between the third and fourth stroke (120 $\mathrm{msec}$ ) and the sporadic but low level optical activity in that interval is suggestive of a second stepped-leader. In this case, again, the complex structure of the returnstroke optical signal could be representative of strong branching associated with a first stroke in a new channel. is seen.

In Figure 5(5) a clear example of an optical dart-leader, return-stroke sequence

In the second, third, and fifth strokes light signals are identified as dart leaders because (1) their luminous intensity is less than the intensity of the returnstroke that follows, (2) they occur about $1.5 \mathrm{msec}$ or less prior to the return-stroke, and (3) they correlate well with the leader E-field change. Nevertheless, the optical signals associated with the dart leader all reach a peak and then decrease before the return-stroke luminosity appears as a well developed, fast-rise signal. This is not, at first sight, what one might expect a dart leader optical signal to look like. There is little reason to expect the luminosity to decrease so abruptly just prior to the return-stroke; in fact, one might expect the light signal to increase as the leader approaches close to Earth. We believe that the large decrease in leader luminosity is not due to any change in the emission associated with the leader, but is caused by a change in the light that emerges from the cloud top as the leader traveling 
downward through the cloud emerges from the cloud base. As shown by Thomason and Krider [1], the fraction of light that escapes through the cloud surface is high when the source is within the cloud, the primary loss being due to absorption, which is negligible in the visible and low in the near infrared. On the other hand, the same authors show that for a light source below a cloud, even a thin cloud, almost all the light will be reflected and very little will emerge from the other side. With this interpretation, the decrease from peak luminosity reached by the leader as indicative of the emergence of the leader into the clear air below the cloud is explained. As observed from scattered light by the U-2, the results appear to be wholly consistent with the conclusions reached by Thomason and Krider.

The E-field change and the optical signals from an intracloud flash that occurred in the same storm at 02:31:05 are shown in Figure 6. This flash was one of short duration lasting only about $250 \mathrm{msec}$. It is very different from the flash to ground shown in Figure $5(0)$ in the pulsative structure of the optical signal. The upward going quasi-steady deflection in the E-field also differentiates it from the ground flash. (The noise on the E-field record is particularly obvious as a cyclic recurrence, masking any small abrupt field changes that may have been present).

An additional 4 intracloud flashes and 14 cloud-to-ground flashes were analyzed. Although there are some variations, the two flashes discussed above are representative of the data acquired during the 5/18/80, Day 138, Arkansas flight.

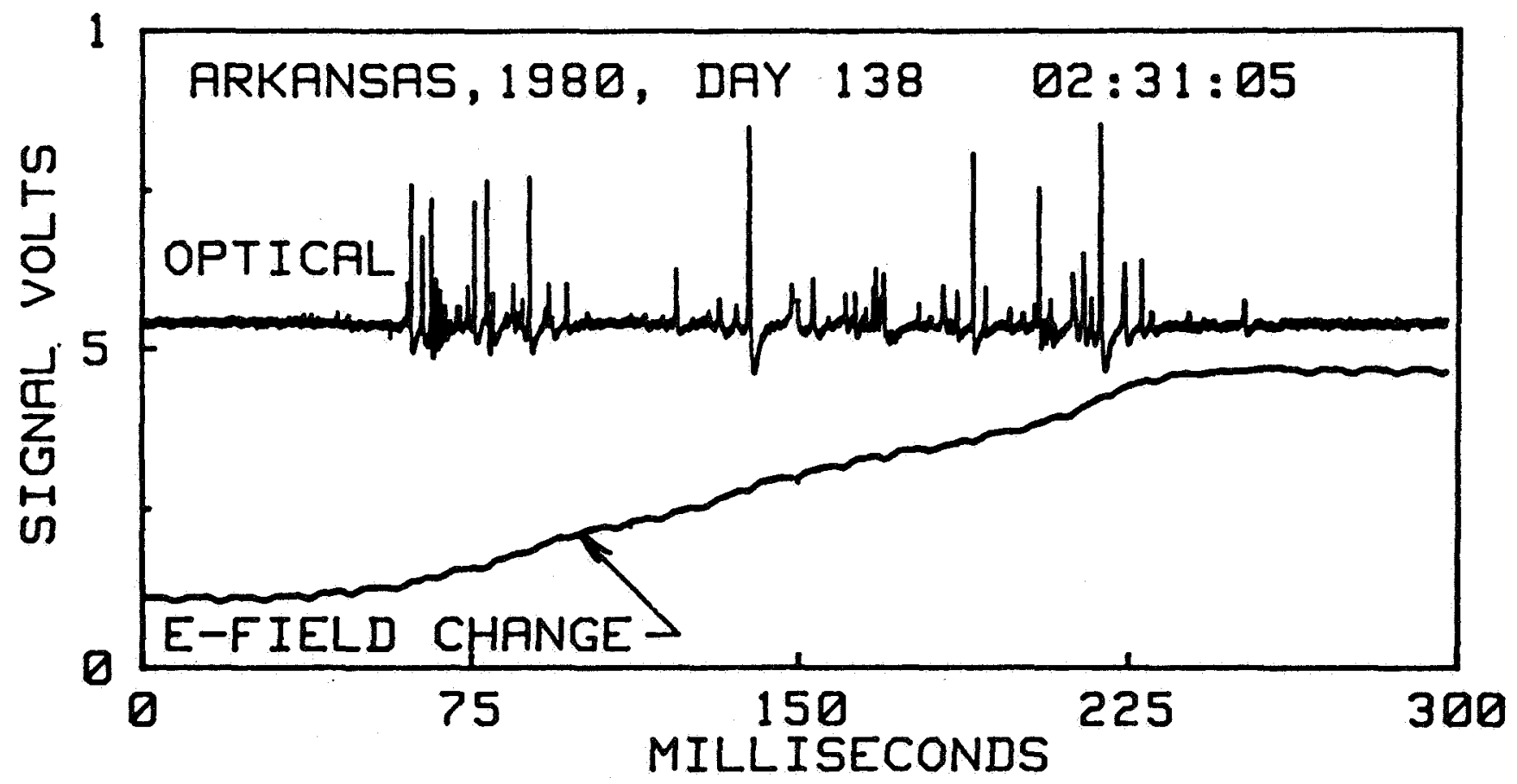

Figure 6. Optical and E field-change signal from an intracloud lightning flash recorded by a U-2 aircraft flying at an elevation of $20 \mathrm{~km}$ above a storm near Little Rock, Arkansas. 


\section{Spectral Data}

Results of the photographic spectral data are summarized in Figures 7 and 8 and Table 1. By chance, the film was moving at the time of the flash, so that the flash was resolved into two channels: one with five strokes and the other with four strokes (Fig. 7). Figure 8 shows the slitless spectral data for one stroke viewed with a video densitometer [20]. The cursor is aligned perpendicular to the spectral lines, and the resulting density profile is shown below the cursor. Note carefully that the density profile is not calibrated so that the relative intensity of the lines cannot be expressed quantitatively. Nevertheless, the relative brightness can be estimated.

Table 1 summarizes the line wavelengths, their qualitative relative intensity, and their identification. In a few cases the weak lines cannot be identified. The most intense emissions occur at $463.0 \mathrm{~nm}$ and $500.5 \mathrm{~nm}$ and are from the confluence of lines from singly ionized nitrogen [21]. The only identified neutral emission is from $\mathrm{H}$-beta at $486.1 \mathrm{~nm}$. Reference to the time-resolved spectrum of Orville (Ref. 22, Part I, Figure 4a) suggests that the lightning channel cooled very rapidly. This is suggested on the basis of the presence of singly ionized lines and the lack of significant neutral emission lines. The latter are emitted at lower temperatures and are characteristic of continuing currents [23]. Unfortunately, it is not known if the observed flash is cloud-to-ground or intracloud.

As might be expected from the spectral data, photographs taken with the color film show the lightning channels to be blue and the clouds illuminated by the lightning to be white or bluish white.

TABLE 1. SPECTRAL LINE IDENTIFICATION

\begin{tabular}{cccc}
$\begin{array}{c}\text { Wavelength } \\
(\mathrm{nm})\end{array}$ & $\begin{array}{c}\text { Strength } \\
\text { (estimated) }\end{array}$ & \multicolumn{3}{c}{$\begin{array}{c}\text { Probable } \\
(\mathrm{nm})\end{array}$} \\
452.7 & $\mathrm{~m}$ & N II (59) & 453.0 \\
463.0 & $\mathrm{~s}$ & N II (5) & 463.0 \\
478.7 & $\mathrm{~m}$ & N II (20) & 480.3 \\
485.0 & $\mathrm{~m}$ & H-beta & 486.1 \\
500.0 & S & N II (19) & 500.5 \\
505.5 & m & N II (4) & 504.5 \\
518.9 & s & N II (66) & 517.9 \\
531.5 & w & & \\
539.4 & w & &
\end{tabular}

Line strengths are listed as strong ( $\mathrm{s})$, medium $(\mathrm{m})$, or weak $(w)$. Probable identifications are assigned a wavelength corresponding to the strongest line in the multiplet (Moore [27]). 


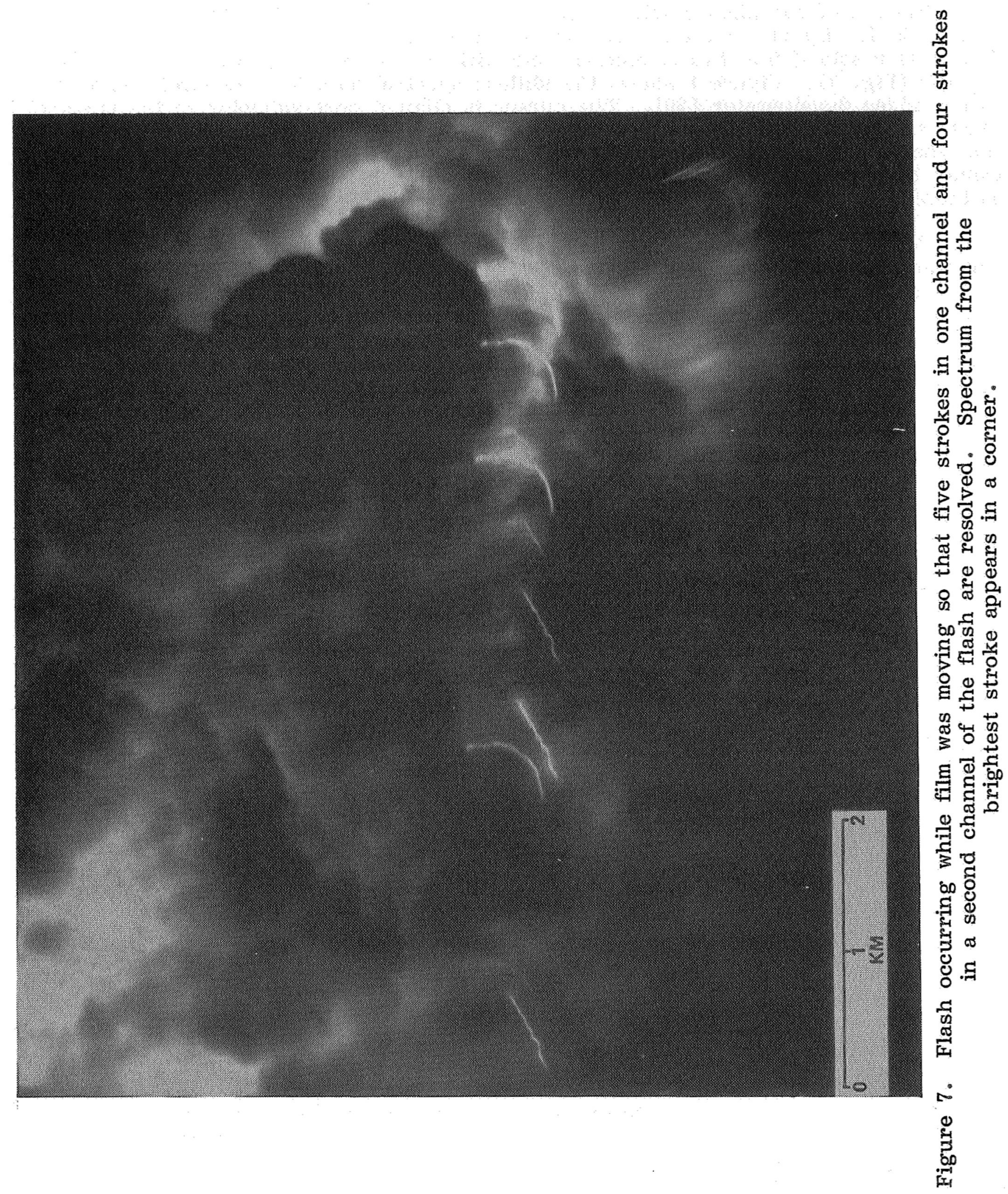




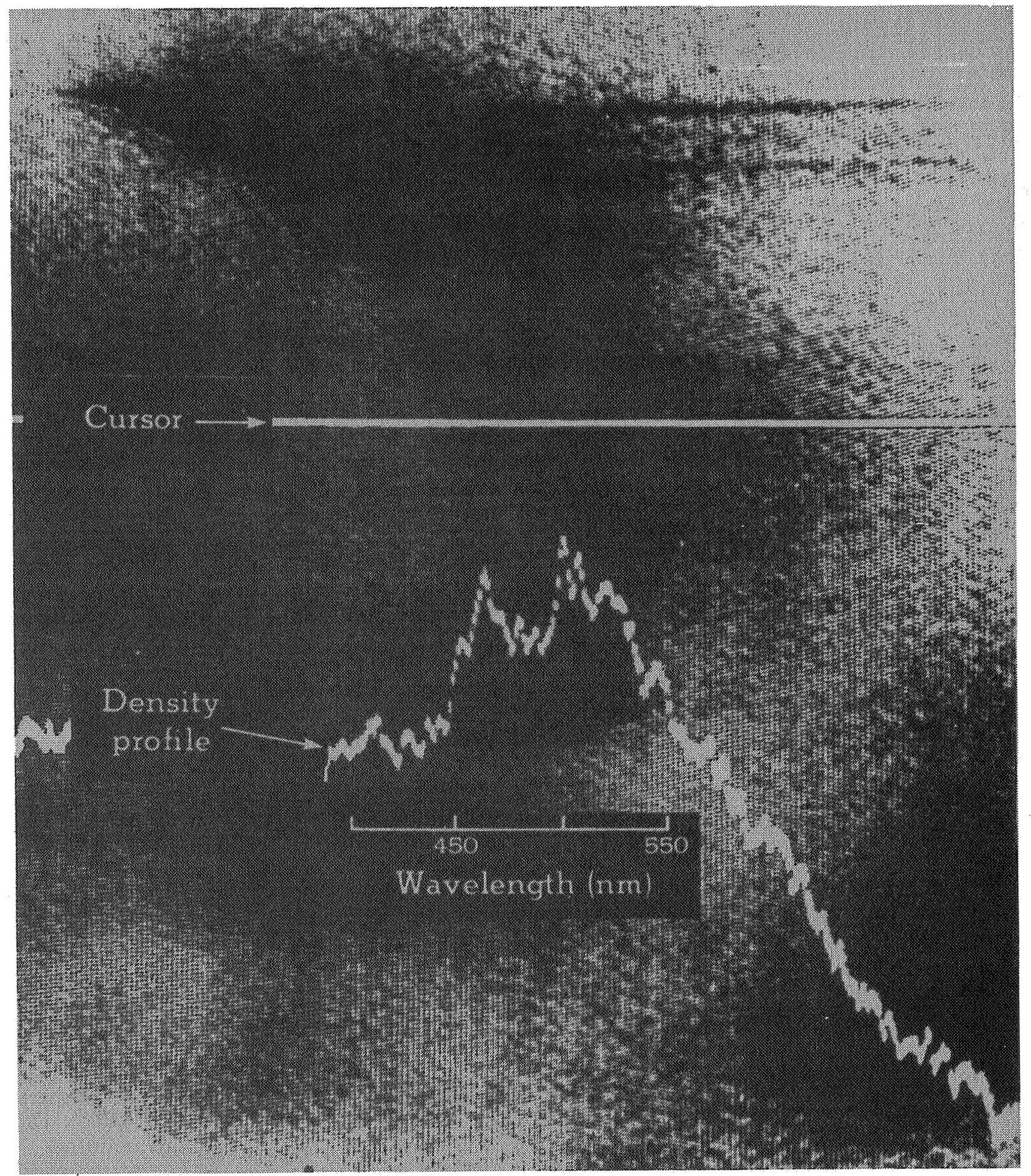

Figure 8. Original slitless spectrum negative is shown on a video densitometer. Density profile is not calibrated, so the relative changes show only qualitative differences. 


\section{The Georgia Storm}

Three hours before the pictures and data were taken over the thunderstorm near Atlanta, Georgia, the map showed a low in southern Indiana $(1,000 \mathrm{mb})$ with a cold front extending south across southern Indiana, central Kentucky, central Tennessee, eastern Alabama to the Florida panhandle. There was a stationary front running east-northeast across southern Indiana, northeastern Ohio, northwestern Pennsylvania, central New York, northern Vermont, New Hampshire and Maine. A squall line existed ahead of the cold front in extreme eastern Tennessee, extending to southwestern North Carolina and western Georgia. The squall line was oriented north to south parallel to the front and $200 \mathrm{~km}$ in advance of it. $500 \mathrm{mb}$ winds of $30 \mathrm{~m} \mathrm{sec}{ }^{-1}$ out of the south southwest prevailed over the cold front and squall line. Representative inflow air into the squall line had a surface based lifted index of -6 , indicative of the ambient unstable conditions.

\section{Photographic Data}

The photographs obtained looking down on this storm over Georgia showed features similar to those observed over Arkansas. The camera was again operated in the open-shutter model, but in this case the film was automatically transported to expose each frame for $11 \mathrm{sec}$. The time of each exposure appears on the frame, and therefore it is possible to correlate the photographs with other data that were taken. One such photograph (Fig. 13), will be discussed in connection with the analysis of the optical and E-field events shown in Figure 12. From the known altitude of the airplane and air speed, it is possible to calculate the altitude of the cloud features by their apparent motion between flashes of lightning. In this storm, such calculations show that the cloud top was about $9 \mathrm{~km}$ beneath the airplane, or at an altitude of about $11 \mathrm{~km} \mathrm{msl}$. The scale indicated on these photographs is probably somewhat more accurate than that on the photographs of the Arkansas storm.

Figure 9 shows a convective cloud turret illuminated entirely by lightning taking place within the cloud. Figure 10 shows several lightning channels visible in the creases of the convective cloud. Figure 11 shows faint lightning channels that apparently terminate in clear air. Figure 13 shows the lightning activity taking place within the cloud when the measurements shown in Figure 12 were made.

\section{Optical and Electric Field-Change Data}

Data acquired during the Atlanta, Georgia, storm on 5/11/81 are of uniformly better quality than the data from the Arkansas storm. An excellent example of the optical, E-field, and line-scan camera data for a flash to ground is shown in Figure $12(0)$, and in the expanded plots for each of the five return-strokes in Figures 12(1) to 12(5). It should be noted that the line-scan spectrometer is a charge-coupled device that accumulates charge until it is read out, the video signal consisting of a contiguous set of "frames" that recur at the rate of 1 every $5 \mathrm{msec}$. The signal in a particular frame is due to the charge that was accumulated by the device during the previous $5 \mathrm{msec}$. Thus, as can be seen in the figures, the spectra usually follow the optical lightning event by as much as $5 \mathrm{msec}$. It should also be noted that the amplitudes of the optical signals of the individual strokes are not necessarily represented faithfully in Figure 12(0). The problem is due to the use of a low sampling rate during the analog-to-digital conversion of the data for that figure. The true relative amplitudes of the stroke signals can be inferred from the expanded Figures 12(1) to $12(5)$. 


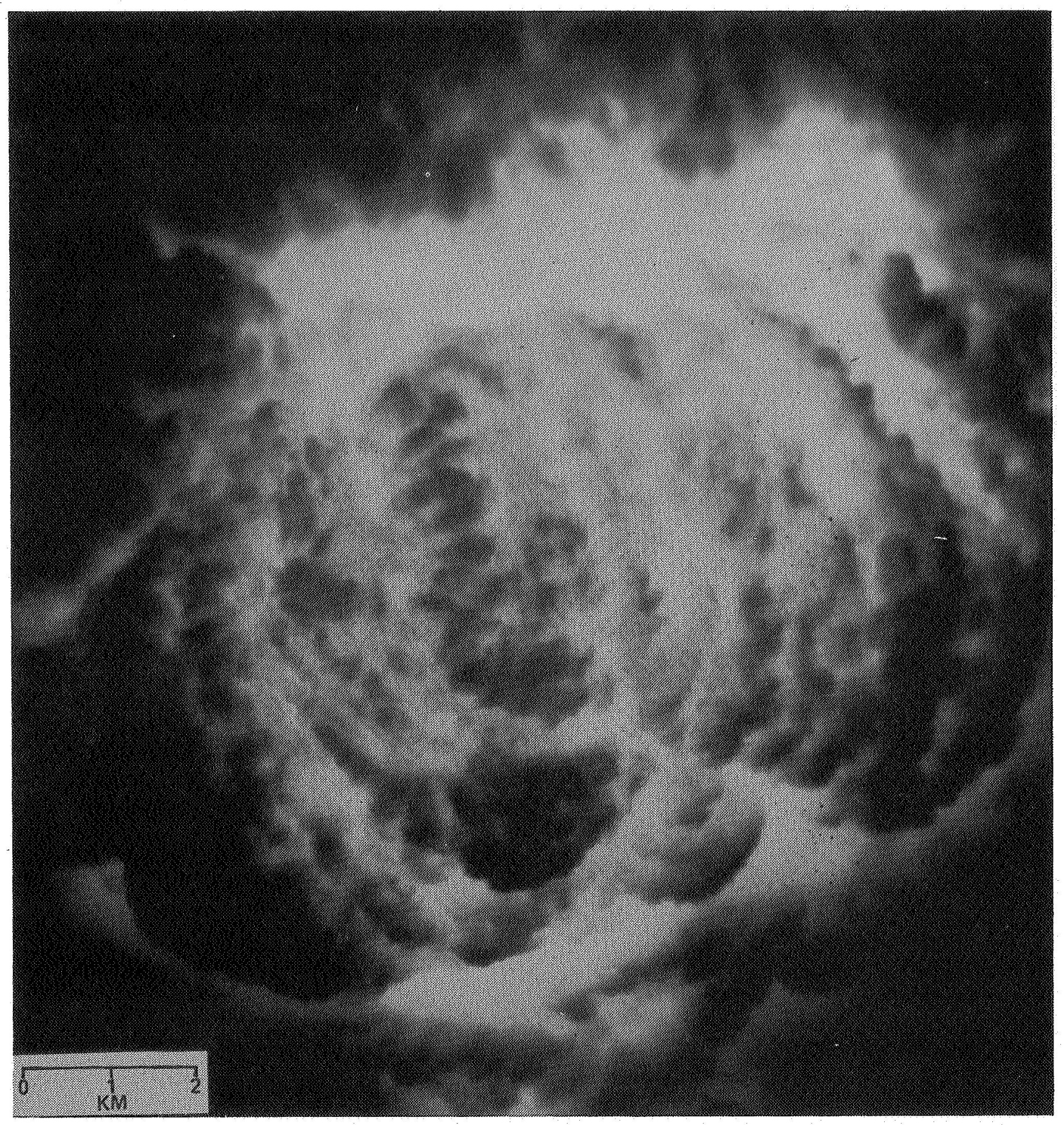

Figure 9. Convective cloud turret of Georgia storm (approximately $11 \mathrm{~km}$ msl altitude) illuminated by lightning within the cloud. 


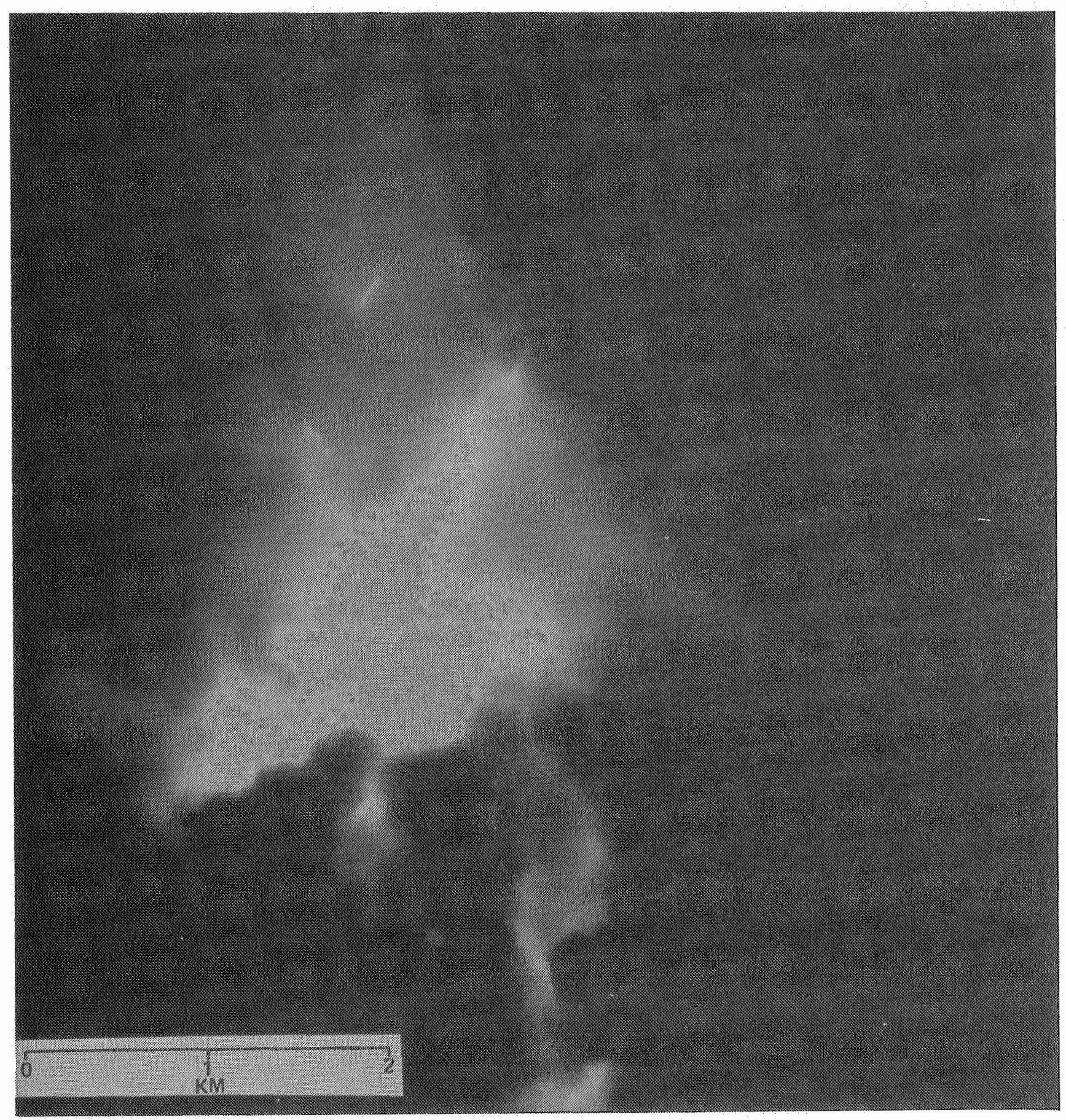

Figure 10. Lightning channels visible in creases of cloud. 


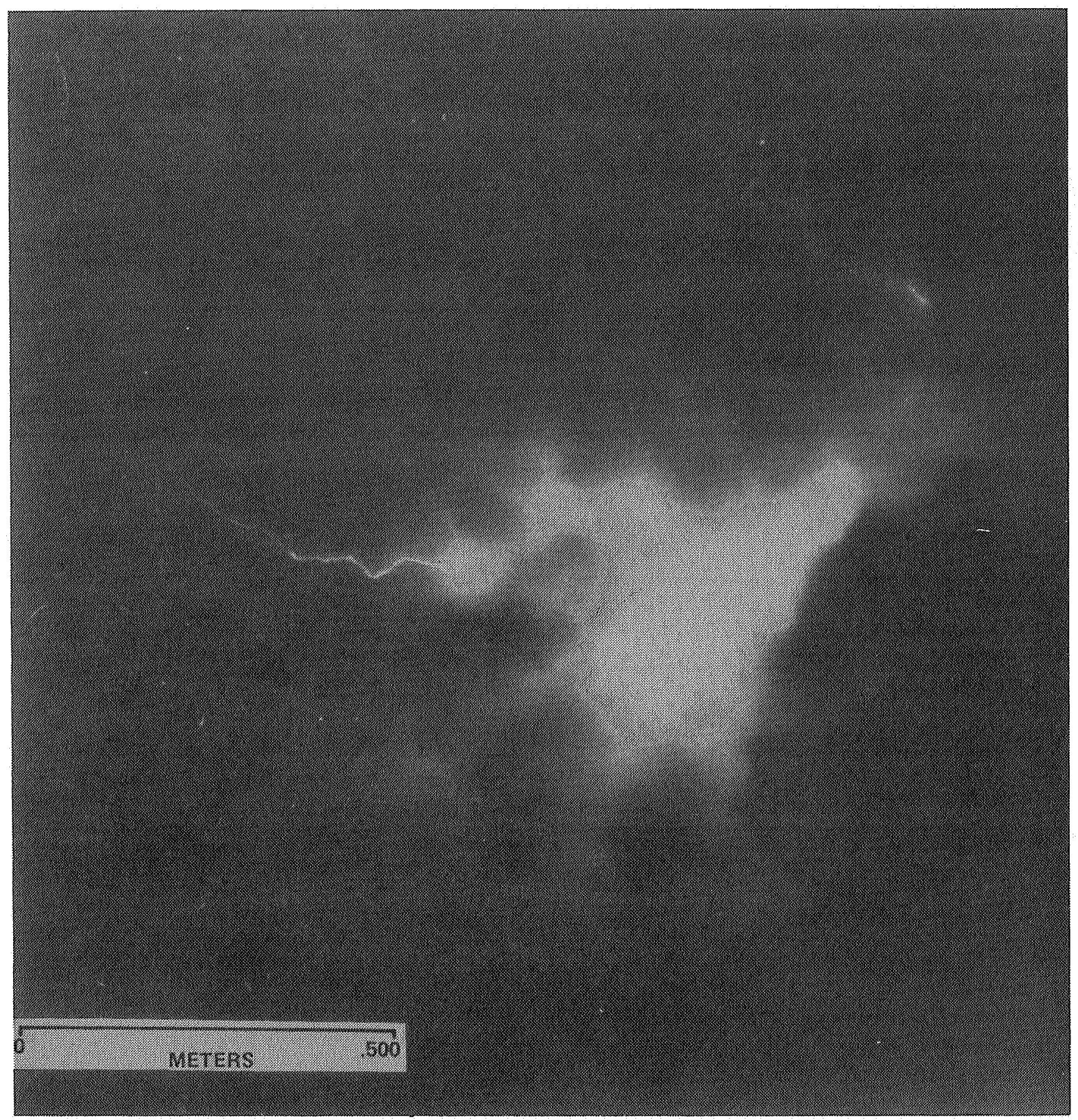

Figure 11. Rather faint lightning channels apparently terminating in clear air. 

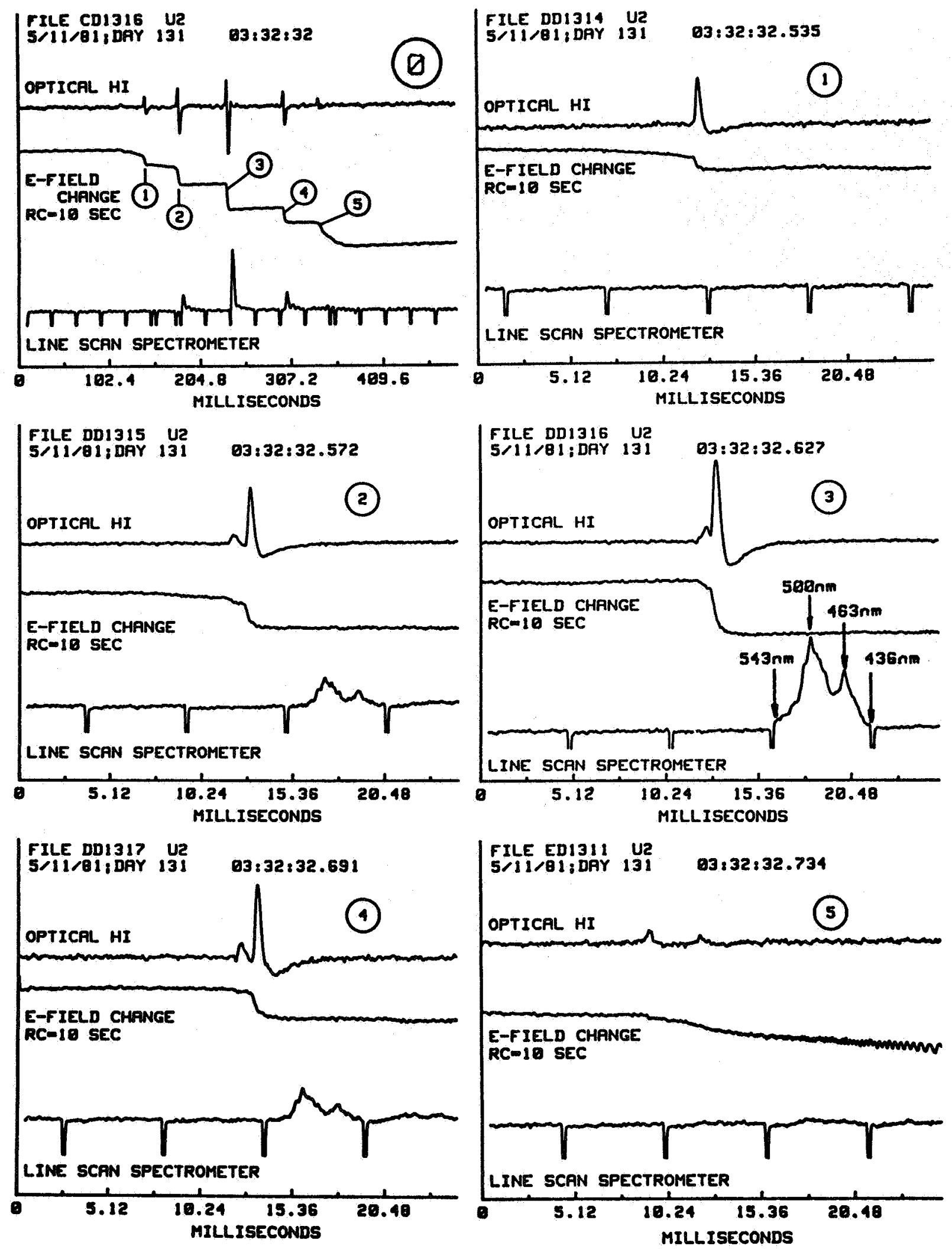

Figure 12. Optical, electric field, and spectral data from a flash to ground over Atlanta, Georgia $(0)$. Signals from the individual strokes are shown expanded in (1) through (5). 


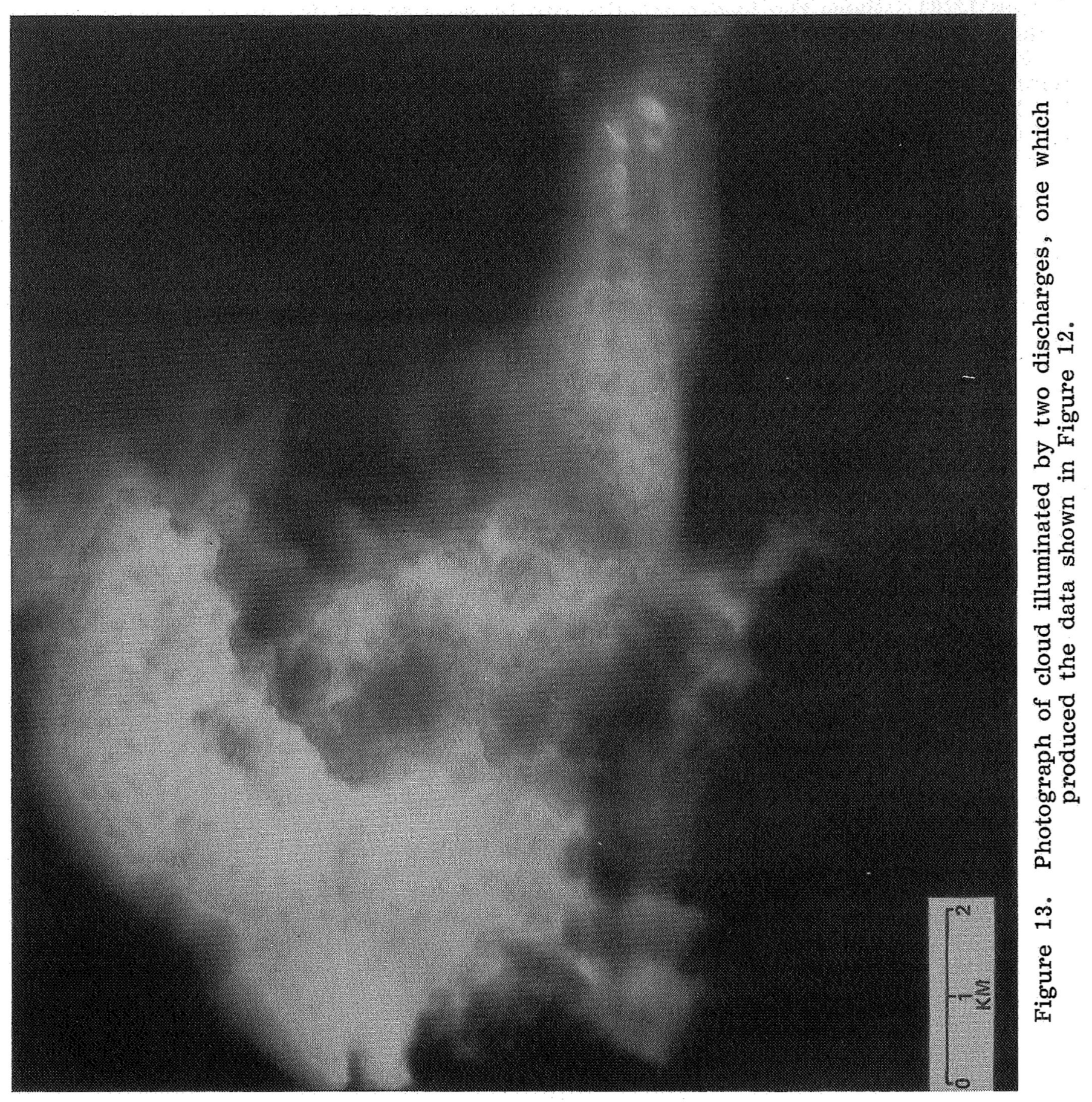


The E-field changes produced by the 5 return-strokes shown in Figure 12(0) are each accompanied by an optical signal, and as in Figure 5(0) of the Arkansas storm, there is little or no detectable optical (or electrical) activity that occurs in the intervals between the strokes. The first stroke of the flash shows evidence of a stepped-leader in both the E-field and the optical signals. This is evident in Figure 12(0), where the leader activity can be seen to last for about $25 \mathrm{msec}$, consistent with measured stepped-leader durations. In the expanded Figure 12(1), the optical signal for the first stroke exhibits only a simple growth and decay (even on a more expanded writeout). The first stroke is not the strongest of the five strokes in either optical or electric field-change amplitude. No spectral signals are above noise in Figure 12(1).

In Figure 12(2) showing the second stroke we see an excellent example of the optical representation of the dart leader event. There is excellent correlation with the dart-leader field change, and the light signal was strong enough for the spectrometer to register a spectrum of the stroke plus leader event.

The third stroke in Figure 12(3) produced the largest field change and the largest light output of all five strokes. The spectral signal is very strong, showing essentially only the two dominant lines in the lightning spectrum: the emission lines of singly ionized nitrogen at 463.0 and $500.5 \mathrm{~nm}$. This stroke also provides an excellent correlation between the optical dart leader and the dart leader field change.

The fourth stroke [Fig. 12(4)] is very much like the second stroke. Again the dart leader is easily distinguished from the return-stroke in the optical signal.

The fifth stroke, shown in Figure 12(5), is small in amplitude and, coupled with the long slow field change, is suggestive of a long continuing current. The oscillations on the latter part of the field change are spurious. Despite the rather small amplitude of the discrete light pulses, there is enough integrated light intensity to produce a signal on the line-scan spectrometer trace, a fact which is further evidence for the existence of a long continuing current.

Additional flashes, both intracloud and cloud-to-ground, were recorded on this flight. They are essentially similar to the flashes already discussed and will therefore not be presented.

\author{
Spectral Data
}

Spectral recordings with the Fairchild line scan camera consistently show the two strong emission features recorded in the photographic data and reproduced in Figure 8. As mentioned in the previous section, these features, centered at 463.0 and $500.5 \mathrm{~nm}$, are produced by emissions from singly ionized nitrogen. No lines were observed that were not recorded in the photographic spectra and listed in Table 1.

\title{
DISCUSSION AND CONCLUSIONS
}

With few exceptions, the photographs that indicate the presence of lightning within the cloud show hard cauliflower-like structures characteristic of vigorous convection. This appears to offer further confirmation of Workman and Reynolds' 
observation [24] that strong convective activity is a requirement for the electrification process responsible for causing lightning.

In some cases, such as those shown in Figures 3 and 11 , it is clearly evident that branches of the lightning channel are terminating in clear air above some portions of the convective cloud. These channels are quite faint in comparison with other much brighter ones that bridge creases in the cloud or with cloud-to-ground strokes photographed from the ground. They probably transport only small amounts of charge. Conceivably there are other very weak discharges above the cloud that are too weak to be seen.

It is impossible to tell from these single photographic images whether the discharge extends vertically upward above the cloud or whether it is proceeding either horizontally or even downward from the point that it issued from the cloud. If second photographs of these channels viewed from another location can be taken from another airplane or from the gorund, it will be possible to determine the threedimensional structure of these discharges.

The detailed fine structure of the cloud tops that can be seen in Figures 1 and 9 is not unexpected. It has long been evident from ground-based observations and in particular from photographs taken from high altitude aircraft during daylight [25] that the penetrative turrets of thunderclouds have a complicated cauliflower-like structure. The surprising feature that is revealed when the cloud is illuminated by lightning from within is that the creases and folds are not shallow structures, but extend downward into the cloud, possibly as much as several kilometers. Obviously this structure indicates the presence of complicated, organized convective air motions. They probably play an important role in cloud microphysical processes and in thunderstorm electrification.

Studies of the optical pulses and the electric field changes accompanying lightning as viewed from above the storm indicate that a great deal of specific information regarding lightning events (leaders, return-strokes, continuing currents, and spectra) is available from the scattered light that finds its way out of the top of the thundercloud.

It is conceivable in this small sample of flashes to ground that the optical sensor was viewing the "naked channel" below the cloud as well as the scattered light from the cloud surface, and that the scattered light alone would not have revealed the excellent detail in the dart leader, return-stroke pairs. To show that the signals presented in Figures 12(0) through 12(5) are the result of scattered light alone emerging from the cloud surfaces, Figure 13, which was taken during the time of the flash to ground identified in Figure 12, is given.

The situation is complicated by the occurrence of another discharge at the time the film was being transported after the event of Figure 12(0) which occurred a 03:32:32. The LED's print the time on the film for $2 \mathrm{sec}$ prior to advancing the film. The film is automatically advanced every $11 \mathrm{sec}$. In this case, the frame containing the photograph of interest was labelled $03: 32: 35$, indicating that the film was transported into position at 03:32:26, $9 \mathrm{sec}$ before the LED's were activated. This $9 \mathrm{sec}$ period contains the cloud-to-ground flash event. An examination of the frame prior to the one of interest confirms the conclusion that the displaced channels present in the photo were photographed after the time 03:32:37, when the film was transported into the next frame. Because all the channels visible are repetitive and substantially displaced from each other, they must have all occurred during the 150 msec interval it takes to transport the film. The displacement is not due to the 
motion of the aircraft which flies at a speed of $200 \mathrm{~m} \mathrm{sec}{ }^{-1}$. The frame area on the film represents a field of view of about $10 \times 10 \mathrm{~km}$ at cloud-top height. For this discharge (03:32:32), which lasted for less than $300 \mathrm{msec}$, the maximum displacement between any two channel images would have to have been less than $60 \mathrm{~m}$, which amounts to a barely detectible broadening of the image.

With the above analysis, the existence of any visible lightning channels associated with the discharge at $03: 32: 32$ can be ruled out. The optical signals in Figures 12(0) through 12(5) were therefore the result of scattered light emerging from the cloud surfaces and not associated with channels in clear view of the sensor.

Although there is time dilation produced by the scattering and channel-lengthening process, it is clear from the analysis that the delays and superpositions of light signals are not of sufficient duration to mask the identity of leaders and return strokes. The leader luminosity always appears to be less than that of the returnstroke; the dart leader occurs as a discrete optical event that precedes the returnstroke by $1.5 \mathrm{msec}$ or (usually) less; return-stroke optical events in a flash are usually separated by periods of tens of milliseconds with practically no luminous events between them. All of these characteristics, based upon optical measurements alone, can be used to write a pattern recognition algorithm that would provide a means of selecting and identifying the ground flashes in a storm, and to sort them out from the intracloud flashes. [A comparison of the optical signal from an intracloud flash (Fig. 6) with that of a cloud-to-ground flash [Figs. 5(0) and 12(0)] show a striking difference between the flash types in the occurrence frequency of pulses of roughly similar amplitudes.] A reasonable estimate of the number of individual return-strokes would also be obtained.

The present analysis appears also to have identified a number of continuing current strokes through the use of a light integration technique (line-scal spectrometer) sampling at $5 \mathrm{msec}$ intervals. More data are needed here, but an intensity ratio between the two lines of singly ionized nitrogen is clearly evident. Whether this ratio changes between intracloud strokes, high-current return-strokes, and continuing current strokes, needs to be studied. If it does, then clearly another method exists for distinguishing return-strokes from intracloud flashes.

\section{SUMMARY}

Observations of nocturnal thunderstorms made from above by a NASA U-2 airplane disclose features of cloud structure and lightning that are not generally visible from the ground. Most, if not all, lightning activity seems to be associated with clouds having strongly convective cauliflower tops. When the lightning occurs deep within the cloud, it can be seen that the folds and creases of the cauliflower top are not superficial surface characteristics, but extend deep into the cloud.

In both of the storms that were studied, lightning channels are visible in the clear air above the cloud in 5 to 10 percent of the lightning events. This finding shows that substances known to be produced by thunderstorm electrical discharges such as $\mathrm{NO}_{\mathrm{x}}$ and $\mathrm{O}_{3}$ can be introduced directly into the stratosphere. More detailed measurements will be required to determine whether or not the quantities introduced are of importance. 
The cause and nature of the discharges above the cloud are not clear. Possibly they may be produced by accumulations of space charge in the clear air above the cloud. Alternatively the discharges may arise solely because of the intense electric fields produced by charges within the cloud. In the latter case the ions introduced by these discharges will have the effect of increasing the electrical conductivity of the air above the cloud and will increase the conduction current that flows from the cloud to the electrosphere.

Lightning spectra observed from above thunderstorms do not appear to differ significantly from similar observations of lightning that have been made from the ground beneath the cloud. More quantitative data at higher resolution may eventually show significant spectral differences between cloud-to-ground and intracloud strokes.

Our findings show that electric field-change data taken with an electric fieldchange meter mounted in an airplane provide data on lightning discharges from above that are quite similar to those obtained from the ground in the past. The transients produced by the photocell optical system correlate well with those provided by the $\mathrm{E}$ field-change meter. It appears that even though $\mathrm{E}$ field-change measurements cannot be made from a satellite, the optical signals from dart leaders, from returnstrokes, and from continuing currents are recognizable, and in some instances, can be used to provide detailed information on the fine structure of lightning. In particular, they can be used to distinguish between cloud-to-ground and intracloud flashes.

This report has emphasized the "optical alone" aspect of sensing lightning discharges from above clouds because of the interest in satellite measurements, especially from geosynchronous altitude. Clearly, optical measurements from a single platform are uniquely suited to provide the space and time resolution necessary to view an Earth hemisphere on which hundreds of thunderstorms may be active simultaneously. Additional scientific objectives have been discussed in Davis, et al. [16], and an update of the presently used instrumentation package, with some preliminary statistics on optical pulse frequency, is given in Christian, et al. [26] . 


\section{REFERENCES}

1. Thomason, L. W. and Krider, E. P.: The Effect of Clouds on the Light Produced by Lightning. J. Atmos. Sci., Vol. 39, 1982, pp. 2051-2065.

2. Wilson, C. T. R.: Investigations on Lightning Discharges and on the Electric Field of Thunderstorms. Phil. Trans. Roy. Soc. A, Vol. 221, 1920, pp. 73-115.

3. Fitzgerald, D. R. and Cunningham, R. M.: Multiple Aircraft Studies of the Electrical Properties of Thunderstorms. Proc. Int. Conf. on Cloud Physics, Tokyo and Sapporo, Japan, 24 May-1 June 1965 (Supplement), pp. 157-162.

4. Vonnegut, B., Moore, C. B., Espinola, R. P., and Blau, H. H., Jr.: Electrical Potential Gradients Above Thunderstorms. J. Atmos. Sco., Vol. 23, 1966, pp. 764-770.

5. Schonland, B. F. J.: The Flight of Thunderbolts. 2nd ed., Clarendon Press, 1964.

6. Chalmers, J. A.: Atmospheric Electricity. 2nd ed., Pergamon Press (New York), 1967, $515 \mathrm{pp}$.

7. Uman, M. A.: Lightning. McGraw-Hill (New York), 1969.

8. Vonnegut, B.: Cloud to Stratosphere Lightning. Weather, Vol. 35, 1980, pp. 59-60.

9. Vaughan, O. H., Jr., and Vonnegut, B.: Lightning to the Ionosphere?

Weatherwise, Vol. 35, 1982, pp. 70-71.

10. Gales, D. M.: Another Account. Weatherwise, Vol. 35, 1982, p. 72.

11. Wilson, C. T. R.: The Electric Field of a Thundercloud and Some of its Effects. Phys. Soc. London Proc., Vol. 37, 1925, pp. 32D-36D.

12. Salanave, L. E.: Lightning and Its Spectrum - An Atlas of Photographs. U. Arizona Press (Tucson), 1980, $160 \mathrm{pp}, 114$ illustrations.

13. Cooper, H. S. F., Jr.: Life in a Space Station II. New Yorker Magazine, September 6, 1976, pp. 34-70.

14. Taranik, J. V. and M. Settle, 1981: Space Shuttle: A New Era in Terrestrial Remote Sensing. Science, Vol. 214, 1981, pp. 619-626.

15. Vonnegut, B.: A Report: Top Weather Event of 1981, Flight of the Space Shuttle. Weatherwise, Vol. 35, 1982, pp. 27-29.

16. Davis, M. H., Brook, M., Christian, H., Heikes, B. G., Orville, R. E., Park, C. G., Roble, R. G., and Vonnegut, B.: Some Scientific Objectives of a Satellite-Borne Lightning Mapper. Bull. Amer. Meteor. Soc., Vol. 63, 1983, pp. 114-119. 
17. Brook. M., Tennis, R., Rhodes, C., Krehbiel, P., Vonnegut, B., and Vaughan, O. H., Jr.: Simultaneous Observations of Lightning Radiations from Above and Below Clouds. Geophys. Res. Letters, Vol. 7, 1980, pp. 267-270.

18. Guo, C., and Krider, E. P.: The Optical and Radiation Field Signatures Produced by Lightning Return Strokes. J. Geophys. Res., Vol. 87, 1982, pp. 8913-8922.

19. Beasley, W. H., Uman, M. A., Jordan, D. M., and Ganesh, C. ; Simultaneous Pulses in Light and Electric Field from Stepped Leaders Near Ground Level. J. Geophys. Res., Vol. 88, 1983, pp. 8617-8619.

20. Orville, R. E., Helsdon, J. R. Jr., and Evans, W. H.: Quantitative Analysis of a Lightning Return Stroke for Diameter and Luminosity Changes as a Function of Space and Time. J. Geophys. Res., Vol. 79, 1974, pp. 4059-4067.

21. Salanave, L. E., Orville, R. E., and Richards, C. N.: Slitless Spectra of Lightning in the Region from 3850 to 6900 Angstroms. J. Geophys. Res., Vol. 67,1962 , pp. 1877-1884.

22. Orville, R. E.: A High-Speed Time-Resolved Spectroscopic Study of the Lightning Return Stroke: Part I. A Qualitative Analysis. J. Atmos. Sci., Vol. 26, 1968, pp. 827-838.

23. Orville, R. E., and Salanave, L. E.: Lightning Spectroscopy-Photographic Techniques. Appl. Optics, Vol. 9, 1970, pp. 1775-1781.

24. Workman. E. J. and Reynolds, S. E.: Electrical Activity as Related to Thunderstorm Cell Growth. Bull. Amer. Meteor. Soc., Vol. 30, 1949, p. 142.

25. Pitts, D. E., Resser, W. K., and Mendlowitz, M. A.: Equivalent Blackbody Temperature of the Tops of a Severe Storm. J. App1. Meteor., Vol. 14, 1975 , pp. 609-618.

26. Christian, H. J., Frost, R. L., Gillaspy, P. H., Goodman, S. J., Vaughan, O. H., Jr., Brook, M., Vonnegut, B., and Orville, R. E.: Observations of Optical Lightning Emissions from Above Thunderstorms Using U-2 Aircraft. Bull. Amer. Meteor. Soc., Vol. 64, 1983, pp. 120-123.

27. Moore, C. E.: A Multiplet Table of Astrophysical Interest - Parts I and II. Princeton University Observatory Report No. PB 151395 (available from Clearinghouse for Federal Scientific and Technical Information). 


\begin{tabular}{|c|c|}
\hline $\begin{array}{l}\text { 1. Report No. } \\
\text { NASA TM-86455 }\end{array}$ & 3. Recipient's Catalog No. \\
\hline \multirow{2}{*}{$\begin{array}{l}\text { 4. Title and Subtitle } \\
\text { Nighttime Observations of Thunderstorm Electrical Activity } \\
\text { From a High Altitude Airplane }\end{array}$} & $\begin{array}{l}\text { 5. Report Date } \\
\text { September } 1984\end{array}$ \\
\hline & 6. Performing Organization Code \\
\hline $\begin{array}{l}\text { 7. Author(s) } \\
\text { M. Brook, } * \text { C. Rhodes, * O. H. Vaughan, Ir., R. E. Orville, ** } \\
\text { and B. Vonnegut** }\end{array}$ & 8. Performing Organization Report No. \\
\hline \multirow{3}{*}{$\begin{array}{l}\text { 9. Performing Organization Name and Address } \\
\text { George C. Marshall Space Flight Center } \\
\text { Marshall Space Flight Center, Alabama } 35812\end{array}$} & $\begin{array}{l}\text { 10. Work Unit No. } \\
\qquad-463\end{array}$ \\
\hline & 11. Contract or Grant No. \\
\hline & 13. Type of Report and Period Covered \\
\hline \multirow{2}{*}{$\begin{array}{l}\text { 12. Sponsoring Agency Name and Address } \\
\text { National Aeronautics and Space Administration } \\
\text { Washington, D.C. } 20546\end{array}$} & Technical Memorandum \\
\hline & 14. Sponsoring Agency Code \\
\hline
\end{tabular}

15. Supplementary Notes

*Geophysical Research Center, New Mexico Institute of Mining and Technology, Socorro, NM 87801 **State University of New York at Albany, Albany, NY 12222 .

16. Abstract

Two sets of observations from a NASA U-2 airplane flying at approximately $20 \mathrm{~km}$ altitude over nocturnal thunderstorms are reported. Photographs show frequent lightning activity in the upper part of the cloud. In some cases, only the diffuse illumination produced by the lightning can be seen. In other cases unobscured segments of lightning channels $1 \mathrm{~km}$ or longer are visible in clear air around and above the cloud. Multiple images of lightning channels, accidentally displaced on the film during transport of the film in the camera, indicate multiple discharges in the same channel. Photographs taken through a diffraction grating show that the lightning has a spectrum similar to that which has been observed in the lower troposphere. Lightning spectra obtained with a slitless line-scan spectrometer show strong singly ionized nitrogen emissions at 463.0 and $500.5 \mathrm{~nm}$. Field changes measured with an electric field-change meter correlate with pulses measured with a photocell optical system.

Optical signals corresponding to dart leader, return stroke, and continuing current events are readily distinguished in the scattered light emerging from the cloud surface. The variation of light intensity with time in lightning events, such as dart leaders, which radiate light first from a location within the cloud and later from outside (beneath) the cloud are consistent with the predicted modification of optical lightning signals by clouds as given by Thomason and Krider [1]. As a result, it appears that satellite based optical sensor measurements cannot provide reliable information on current rise times in return strokes. On the other hand, discrimination between cloud-to-ground and intracloud flashes and the counting of ground strokes is possible using the optical pulse pairs which have been identified with leader, return-stroke events in the cloud-to-ground flashes studied. If confirmed by further studies as a regularly identifiable occurrence, the pulse pairs together with other criteria, could form the basis for the reliable identification of ground strokes from a satellite by the use of an optical detector alone.

It has been found unexpectedly that a multitude of weak lightning channels commonly exists in the clear air above or around cloud tops. This indicates that lightning is capable of introducing chemical species, ions, and space charge directly into the upper troposphere and lower stratosphere.

\begin{tabular}{|c|c|c|c|c|}
\hline \multicolumn{2}{|c|}{$\begin{array}{l}\text { 17. Key Words (Suggested by Author(s)) } \\
\text { Lightning research } \\
\text { Aircraft lightning instrumentation } \\
\text { Meteorology }\end{array}$} & \multicolumn{3}{|c|}{$\begin{array}{l}\text { 18. Distribution Statement } \\
\qquad \begin{array}{l}\text { Unclassified - Unlimited } \\
\text { STAR Category } 35\end{array}\end{array}$} \\
\hline $\begin{array}{l}\text { 19. Security Classif. (of this report) } \\
\text { Unclassified }\end{array}$ & & of this page) & $\begin{array}{l}\text { 21. No. of Pages } \\
32\end{array}$ & $\begin{array}{l}\text { 22. Price } \\
\mathrm{AO} 3\end{array}$ \\
\hline
\end{tabular}

